\title{
Magnitude and determinants of obstetric case fatality rate among women with the direct causes of maternal deaths in Ethiopia: a national cross sectional study
}

Ayele Geleto ${ }^{1,2^{*}}$, Catherine Chojenta ${ }^{2}$, Tefera Taddele ${ }^{3}$ and Deborah Loxton ${ }^{2}$

\begin{abstract}
Background: In sub-Saharan Africa, maternal death due to direct obstetric complications remains an important health threat for women. A high direct obstetric case fatality rate indicates a poor quality of obstetric care. Therefore, this study was aimed at assessing the magnitude and determinants of the direct obstetric case fatality rate among women admitted to hospitals with direct maternal complications.

Methods: In 2015, the Ethiopian Public Health Institute conducted a national survey about emergency obstetric and newborn care in which data about maternal and neonatal health indicators were collected. Maternal health data from these large national dataset were analysed to address the objective of this study. Descriptive statistics were used to present hospital specific characteristics and the magnitude of direct obstetric case fatality rate. Logistic regression analysis was performed to examine determinants of the magnitude of direct obstetric case fatality rate and the degree of association was measured using an adjusted odds ratio with $95 \%$ confidence interval at $p<0.05$.

Results: Overall, 335,054 deliveries were conducted at hospitals and 68,002 (20.3\%) of these women experienced direct obstetric complications. Prolonged labour (23.4\%) and hypertensive disorders (11.6\%) were the two leading causes of obstetric complications. Among women who experienced direct obstetric complications, 435 died, resulting in the crude direct obstetric case fatality rate of $0.64 \%$ (95\% Cl: $0.58-0.70 \%)$. Hypertensive disorders (27.8\%) and maternal haemorrhage (23.9\%) were the two leading causes of maternal deaths. The direct obstetric case fatality rate varied considerably with the complications that occurred; highest in postpartum haemorrhage (2.88\%) followed by ruptured uterus (2.71\%). Considerable regional variations observed in the direct obstetric case fatality rate; ranged from $0.27 \%$ (95\% Cl: $0.20-0.37 \%$ ) at Addis Ababa city to $3.82 \%$ (95\% Cl: $1.42-8.13 \%$ ) at the Gambella region. Type of hospitals, managing authority and payment required for the service were significantly associated with the magnitude of direct obstetric case fatality rate.

\footnotetext{
* Correspondence: ayele.bali@uon.edu.au

'School of Public Health, College of Health and Medical Sciences, Haramaya University, Harar, Ethiopia

${ }^{2}$ Research Centre for Generational Health and Ageing, School of Medicine and Public Health, Faculty of Health and Medicine, the University of Newcastle, Newcastle, Australia

Full list of author information is available at the end of the article
}

(c) The Author(s). 2020 Open Access This article is licensed under a Creative Commons Attribution 4.0 International License, which permits use, sharing, adaptation, distribution and reproduction in any medium or format, as long as you give appropriate credit to the original author(s) and the source, provide a link to the Creative Commons licence, and indicate if changes were made. The images or other third party material in this article are included in the article's Creative Commons licence, unless indicated otherwise in a credit line to the material. If material is not included in the article's Creative Commons licence and your intended use is not permitted by statutory regulation or exceeds the permitted use, you will need to obtain permission directly from the copyright holder. To view a copy of this licence, visit http://creativecommons.org/licenses/by/4.0/ The Creative Commons Public Domain Dedication waiver (http://creativecommons.org/publicdomain/zero/1.0/) applies to the data made available in this article, unless otherwise stated in a credit line to the data. 
(Continued from previous page)

Conclusions: The high direct obstetric case fatality rate is an indication for poor quality of obstetric care. Considerable regional differences occurred with regard to the direct obstetric case fatality rate. Interventions should focus on quality improvement initiatives and equitable resource distribution to tackle the regional disparities.

Keywords: Major direct causes, Maternal deaths, Case fatality rate, Ethiopia, Hospitals

\section{Background}

Obstetric complications are a global health threat for women affecting about a sixth of all pregnant mothers [1]. An obstetric complication is defined as an acute condition arising from either a direct or indirect cause of maternal death. Direct obstetric complications include maternal complications such as maternal haemorrhage, obstructed labour, sepsis, complications of abortion, preeclampsia or eclampsia, ectopic pregnancy, postpartum sepsis, and ruptured uterus [2]. Indirect obstetric complications are the exacerbation of pre-existing maternal health conditions or illnesses including anaemia, malaria and other health conditions, that a woman acquires during pregnancy and childbirth and are not directly caused by the pregnancy [3]. Unless appropriately managed, several obstetric complications that arise during pregnancy and childbirth can end in maternal deaths [3]. Therefore, reduction of maternal mortality has become the top global health priority that can be achieved through the provision of quality obstetric care [4].

Reports from various countries show that maternal deaths remain the most important public health problem in sub-Saharan Africa [5]. A recent report jointly released by the WHO, UNICEF, UNFPA, World Bank Group, and the United Nations Population Division revealed that the global MMR had declined by $38.4 \%$ from 2000 to 2017 with an average annual reduction rate of $2.9 \%$. According to this report, although sub-Saharan Africa achieved a substantial reduction, still MMR remains at higher magnitude than other regions. In Ethiopia, MMR was 401 per 100,000 live births in 2017 [6]. With its current MMR, Ethiopia is one of the countries with the highest MMR and almost all of these deaths are accounted to the direct obstetric complications [7]. Almost all (99\%) of the global maternal mortality has occurred in low-income countries and $66 \%$ of these deaths are accounted for by countries in sub-Saharan Africa [8].

Direct obstetric case fatality rate (DOCFR) is defined as the proportion of women who are admitted to a hospital or an emergency obstetric care facility with direct obstetric complications, or who develop such conditions after admission, and die before discharge [9]. The WHO recommends the DOCFR as a useful crude indicator of the quality of obstetric care provided at a particular health facility. The DOCFR is estimated in such a way that the number of women who experienced direct obstetric complications is used as the denominator and the numerator being the number of women who died due to direct obstetric complications. Accordingly, obstetric services are said to be of good quality if the DOCFR is less than 1\% [10]. However, several study findings in most sub-Saharan African countries show a higher DOCFR than the recommended threshold. For example, researchers in Nigeria showed that, DOCFR was 3.2\% [11] while findings of a study in Malawi revealed that DOCFR was 2.0\% [12]. In Ethiopia, the magnitude of DOCFR for women with major direct obstetric complications was reported to be $2 \%$ [13].

Ethiopia is one of the countries in the Horn of Africa with a population of different cultures, ethnicities and religions [14]. According to the United Nations Worldometers (2019), the total population of Ethiopia was $109,302,118$ as at March 2019. Ethiopia is the twelfth most populous country in the world, and the second in Africa, next to the Nigeria [15]. Currently, the total fertility rate is 4.6 , the contraceptive prevalence rate for currently married women is $36 \%$, and the unmet need for family planning is $22 \%$ [7]. Only $74 \%$ pregnant women visited a health facility for the first antenatal care while only $43 \%$ of pregnant mothers visited a facility four times. Only $34 \%$ of women were reported as meeting the Safe Motherhood Programmes' recommendation of receiving a postnatal care check within two days of delivery [16].

Evidence about DOCFR is assumed the better indicators for designing, monitoring and evaluating the quality of maternal health interventions. In Ethiopia, despite the high maternal mortality rate, limited literature exists about the DOCFR. To the authors' knowledge, determinants of the DOCFR has not been studied in Ethiopia. Therefore, the aim of this study was to assess the magnitude of the DOCFR and its determinants among women admitted to hospitals in Ethiopia.

\section{Methods}

\section{Study area and period}

This study utilized a large public dataset available at the Ethiopian Public Health Institute (EPHI). The EPHI is a 
large-scale research institute, which undertakes various basic and operational researches on the priority health agenda to generate and disseminate scientific knowledge that help in improving the health of the population. The EPHI conducted a national cross-sectional survey titled 'assessment of emergency obstetric and newborn care in Ethiopia' in 2016. With this project, different data about maternal and neonatal health indicators were collected from health facilities' logbooks.

\section{Study participants}

In the 2016 national survey, the EPHI included all public and private health facilities found in the country, which were deemed functional and offered delivery services. There were 3804 health facilities that were included in the survey to collect data about maternal and neonatal health indicators. However, the current study analysed the data of all governmental/public and private hospitals, of which there were 293 at the time of data collection. The data that were collected from 30 (10.2\%) specialized hospitals, 103 (35.2\%) general hospitals and 160 (54.6\%) primary hospitals were included.

\section{Inclusion and exclusion criteria}

The data about number and type of obstetric complications, maternal deaths and all deliveries conducted throughout 2015 among all hospitals found in Ethiopia were included in the analysis. The data of all public/government and private hospitals were included with the exclusion of maternal data collected from the lower level facilities including clinics and health centres. In Ethiopia, women who have experienced obstetric complications are often referred to hospitals where they can receive specialized treatment. Therefore lower level health facilities were not included in the analysis since information of the majority of women who sustained obstetric complications can be obtained from hospitals.

\section{Nature of the data}

The EPHI collected data about the performance of the Emergency Obstetric and Newborn Care (EmONC) signal functions at a particular hospital using a standardized questionnaire. The EPHI collected the data from hospitals' registers and records within the reference period of January-December 2015 inclusive. The available dataset included the number and mode of deliveries, number of women who experienced different types of direct obstetric complications and associated maternal deaths that occurred in each hospital. The dataset also had different facility-specific characteristics including type of hospital, managing authority, location of the hospitals and fulfilment of basic facility infrastructure.

The primary outcome variable is the DOCFR, the proportion of women who are admitted to a hospital or an emergency obstetric care facility with major direct obstetric complications, or who develop such complications after admission, and die before discharge [9]. Then hospitals' specific characteristics such as type, managing authority, and location of the hospitals and fulfilment of basic facility infrastructure were assessed for whether they predict the magnitude of the DOCFR in hospitals or not.

\section{Operational definitions}

- Major direct obstetric complications: In this study, the following were considered as major direct obstetric complications: Antepartum Haemorrhage $(\mathrm{APH})$, Postpartum Haemorrhage (PPH), retained placenta, prolonged/obstructed labour, postpartum sepsis (infections that a women acquire during labour, childbirth and immediate postpartum period), ruptured uterus, severe eclampsia/ preeclampsia, complications of abortion and ectopic pregnancy [9].

- Other direct obstetric complications: These complications include premature rupture of membrane, post-term labour, cord prolapse, breech presentation, and other possible problems that were not considered as a major direct cause of maternal deaths [17].

- Direct Obstetric Case Fatality Rate (DOCFR): the proportion of women who are admitted to a hospital or an EmOC facility with the major direct obstetric complications or who develop such complications after admission and die before discharge [9].

- DOCFR $\geq 1$ : is a crude indicator for poor quality of obstetric services provided at a particular health facility [10].

\section{Data analysis}

Initially, descriptive statistics including means, percentages, frequency tables and ratios were used to describe facility specific characteristics and the magnitude of the DOCFR. Then logistic regression analysis was conducted to examine the association between the DOCFR and hospital-specific characteristics. Maternal deaths due to direct obstetric complications that were reported in all hospitals during 2015 were included to determine the magnitude of the DOCFR. For the analysis purpose, the magnitude of the DOCFR was calculated for each hospital according to the WHO definition, the proportion of women admitted to a hospital or an EmOC facility with direct obstetric complications, or who developed such complications after admission, and died before discharge [9]. Using the number of women who experienced direct obstetric complications as the denominator, we calculated the DOCFR, the numerator being the 
number of maternal deaths attributed to direct obstetric causes. Hospitals were dichotomized based on the WHO recommendation of DOCFR: hospitals with DOCFR $\geq 1$ (hospitals with unfavourable outcomes) and hospitals with DOCFR $<1$ (hospitals with favourable outcomes). First, we conducted univariate logistic regression analysis to assess the presence of association between the magnitude of the DOCFR and hospital-specific characteristics. Facility-level variables that were significantly associated with the magnitude of the DOCFR in the univariate analysis were successively included in a multivariate model, using a backwards-stepwise elimination to select variables. For all models fitted, we used generalised linear model for the multilevel analysis by using Stata version 15 statistical software. The degree of association between variables was measured using an adjusted odds ratio with 95\% confidence interval and association was declared significant at $p$ value $<0.05$.

\section{Ethical clearance}

The Ethiopian national survey titled 'Assessment of emergency obstetric and newborn care in Ethiopia' was granted ethical approval from the Scientific and Ethical Review Office of the EPHI (approval number: EPHI-613-728) on 6-Jun-2016. Ethical approval for this analysis was obtained from the Human Research Ethics Committee (HREC) of The University of Newcastle, Australia (approval number: H-2018-0245) on 15-Aug-2018. The protocol developed to conduct this analysis had received ethical approval from the Scientific and Ethical Review Office of the EPHI before the data were accessed (Protocol number: EPHI-IRB-048-2018) on 25-July-2018.

\section{Results}

Hospitals characteristics

The current study presented the magnitude of DOCFR and associated factors in 293 hospitals found in nine regional states and two city administrations of Ethiopia. Nearly a fourth $(\mathrm{N}=173 ; 24.9 \%)$ of the hospitals were from Oromia region and $30(10.2 \%)$ of the hospitals were referral specialized hospitals. Two hundred and thirty-five $(80.2 \%)$ hospitals were public hospitals while the remaining were private facilities. Geographically, 272 (92.8\%) hospitals were located in urban centres. The majority of the hospitals, $(N=207 ; 70.6 \%)$ had initiated the maternal death review and reporting system (MDRS); a health reform used to continuously notify, review, analyse and respond to maternal deaths (Table 1).

\section{Direct obstetric complications and associated maternal deaths}

Overall, 335,054 deliveries were conducted in all hospitals in Ethiopia and 68,002 women experienced direct obstetric complications, giving the crude incidence rate
Table 1 Characteristics of hospitals included in the study, Ethiopia, 2015

\begin{tabular}{|c|c|c|}
\hline Variables & Number of hospitals & Percent \\
\hline \multicolumn{3}{|l|}{ Region } \\
\hline Addis Ababa & 33 & 11.3 \\
\hline Afar & 6 & 2.0 \\
\hline Amhara & 56 & 19.1 \\
\hline Benishangul Gumz & 3 & 1.0 \\
\hline Dire Dawa & 6 & 2.0 \\
\hline Gambella & 1 & .3 \\
\hline Harari & 6 & 2.0 \\
\hline Oromia & 73 & 24.9 \\
\hline SNNPR & 60 & 20.5 \\
\hline Somali & 10 & 3.4 \\
\hline Tigray & 39 & 13.3 \\
\hline \multicolumn{3}{|l|}{ Type of hospital } \\
\hline Referral/specialized & 30 & 10.2 \\
\hline General hospital & 103 & 35.2 \\
\hline Primary hospital & 160 & 54.6 \\
\hline \multicolumn{3}{|l|}{ Managing authority } \\
\hline Public/Government & 235 & 80.2 \\
\hline Private & 58 & 19.8 \\
\hline \multicolumn{3}{|l|}{ Location } \\
\hline Urban & 272 & 92.8 \\
\hline Rural & 21 & 7.2 \\
\hline \multicolumn{3}{|c|}{ Availability of electricity } \\
\hline No & 12 & 4.1 \\
\hline Yes & 281 & 95.9 \\
\hline \multicolumn{3}{|l|}{ Availability of water } \\
\hline No & 10 & 3.4 \\
\hline Yes & 281 & 95.9 \\
\hline \multicolumn{3}{|c|}{ Availability of functional toilet } \\
\hline No & 8 & 2.7 \\
\hline Yes & 285 & 97.3 \\
\hline \multicolumn{3}{|c|}{ Formal payment required for the service ${ }^{a}$} \\
\hline No & 89 & 30.4 \\
\hline Yes & 204 & 69.6 \\
\hline \multicolumn{3}{|c|}{ Has the hospital implemented MDRS } \\
\hline No & 86 & 29.4 \\
\hline Yes & 207 & 70.6 \\
\hline
\end{tabular}

MDRS Maternal Death Review and Reporting System

a: In Ethiopia, all maternal health services are given free of charge in public health facilities. However, some hospitals might request women to purchase some medical supplies and drugs

of 203 per 1000 deliveries $(68,002 / 335054)$. Major direct obstetric complications accounted for 40,080 (58.9\%) of the cases while $27,922(41.1 \%)$ of women experienced 
Total deliveries conducted at all hospitals in Ethiopia in $2015=335,054$

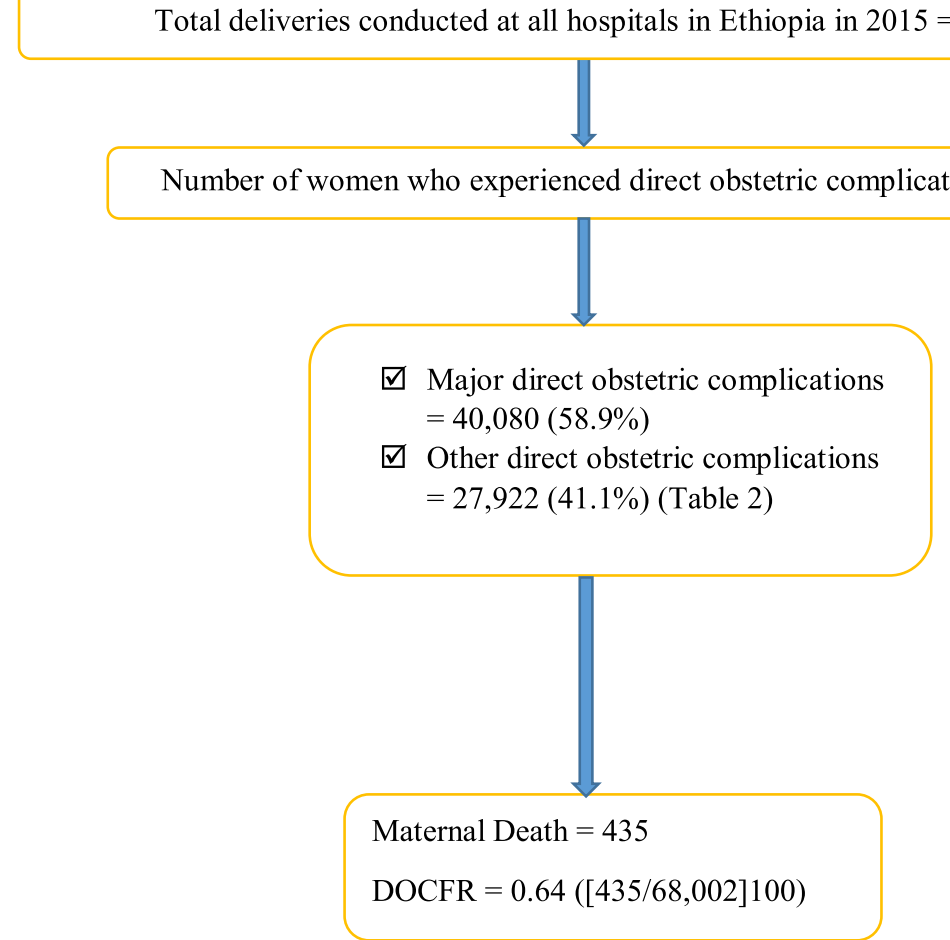

Fig. 1 The number of childbirth, mode of delivery and number of women who experienced obstetric complications at hospitals in Ethiopia, 2015. SVD: Spontaneous Vaginal Delivery; AVD: Assisted Vaginal Delivery; CS: Caesarean Section; RU: Ruptured Uterus Major direct obstetric complications: constitutes antepartum haemorrhage, postpartum haemorrhage, retained placenta, obstructed labour, postpartum sepsis, ruptured uterus, hypertensive disorders, complications of abortion and ectopic pregnancy. Other direct obstetric complications: These include premature rupture of membrane, postterm labour, cord prolapse, breech presentation, and other possible problems that were not considered as a major direct obstetric complication

other direct obstetric complications (Fig. 1). Prolonged labour was the leading cause of major direct obstetric morbidity, accounting for $23.4 \%$ of the total cases. Hypertensive disorders was the second most frequent cause of major direct maternal morbidity as $11.6 \%$ of mothers experienced this condition (Table 2).

Of women who experienced direct obstetric complications, 435 died, resulting in crude national DOCFR of

Table 2 Magnitude of direct obstetric complications and associated maternal death among hospitals in Ethiopia, 2015

\begin{tabular}{|c|c|c|c|c|}
\hline Direct obstetric complications & Number of cases (\%) & Direct obstetric complication rate ${ }^{a}$ & Number of death (\%) & DOCFR in \% $(95 \% \mathrm{Cl})$ \\
\hline Antepartum Haemorrhage & $4462(6.5)$ & $13.3(12.9-13.7)$ & $23(5.3)$ & $0.51(0.32-0.77)$ \\
\hline Postpartum Haemorrhage & $2811(4.1)$ & $8.4(8.1-8.7)$ & $81(18.6)$ & $2.88(2.29-3.57)^{*}$ \\
\hline Retained placenta & $2201(3.2)$ & $6.5(6.3-6.8)$ & $4(0.9)$ & $0.18(0.04-0.46)$ \\
\hline Prolonged labour & $15,875(23.4)$ & $47.4(46.7-48.2)$ & $25(5.7)$ & $0.16(0.10-0.23)$ \\
\hline Rupture of uterus & $1516(2.2)$ & $4.5(4.3-4.7)$ & $41(9.5)$ & $2.71(1.95-3.65)^{*}$ \\
\hline Postpartum sepsis & $1460(2.2)$ & $4.3(4.1-4.6)$ & $17(3.9)$ & $1.16(0.67-1.85)$ \\
\hline Hypertensive disorder & $7912(11.6)$ & $23.6(23.1-24.2)$ & $121(27.8)$ & $1.53(1.27-1.82)^{*}$ \\
\hline Abortion complications & $2042(3.0)$ & $6.1(5.8-6.4)$ & $6(1.5)$ & $0.29(0.11-0.64)$ \\
\hline Ectopic pregnancy & $1801(2.7)$ & $5.3(5.1-5.6)$ & $0(0.0)$ & - \\
\hline Other direct causes & $27,922(41.1)$ & $83.5(82.5-84.4)$ & $117(26.8)$ & $0.42(0.34-0.50)$ \\
\hline Total & $68,002(100)$ & 203.3 (201.9-204.7 & $435(100)$ & $0.64(0.58-0.70)$ \\
\hline
\end{tabular}

DOCFR Direct Obstetric Case Fatality Rate

*statistically significantly greater DOCFR than $1 \%$ (the recommended threshold by the World Health Organization); $p<0.05$

-: there were no maternal deaths due to ectopic pregnancy hence DOCFR was not calculated

${ }^{a}$ Direct obstetric complication rate was estimated by the complications per 1000 births 
Table 3 Regional distribution of direct obstetric case fatality rate among hospitals in Ethiopia, 2015

\begin{tabular}{llll}
\hline Regions in Ethiopia & $\begin{array}{l}\text { Number of } \\
\text { women with } \\
\text { complications }\end{array}$ & $\begin{array}{l}\text { Maternal deaths } \\
\text { due to the } \\
\text { complication (n) }\end{array}$ & $\begin{array}{l}\text { DOCFR in } \\
\text { percent with } \\
95 \% \mathrm{Cl}\end{array}$ \\
\hline Addis Ababa & 14,453 & 39 & $0.27(0.20-0.37)$ \\
Afar & 358 & 5 & $1.39(0.45-3.22)$ \\
Amhara & 11,263 & 89 & $0.79(0.63-0.97)$ \\
Benishangul Gumuz & 1302 & 4 & $0.30(0.08-0.78)$ \\
Dire Dawa & 1437 & 8 & $0.55(0.24-1.09)$ \\
Gambella & 157 & 6 & $3.82(1.42-8.13)^{*}$ \\
Harari & 1384 & 15 & $1.08(0.61-1.78)$ \\
Oromia & 17,084 & 128 & $0.74(0.62-0.89)$ \\
SNNPR & 12,942 & 82 & $0.63(0.50-0.78)$ \\
Somali & 1710 & 29 & $1.69(1.13-2.42)^{*}$ \\
Tigray & 5912 & 30 & $0.51(0.34-0.72)$ \\
Total & $\mathbf{6 8 , 0 0 2}$ & $\mathbf{4 3 5}$ & $\mathbf{0 . 6 3}(\mathbf{0 . 5 8 - 0 . 7 0 )}$
\end{tabular}

SNNPR Southern Nations Nationalities and People Region

DOCFR Direct Obstetric Case Fatality Rate

*statistically significantly greater DOCFR than $1 \%$ (the recommended threshold by the World Health Organization); $p<0.05$

0.64 (95\% CI: $0.58-0.70)$ per 100 mothers $(435 / 68,002)$. That is, a general ratio of 1 death for every 156 cases of direct obstetric complications was observed. Hypertensive disorders was the leading cause of direct maternal mortality, accounting for $27.8 \%$ of the overall maternal deaths. Obstetric haemorrhage was the second most frequent direct cause of maternal mortality, accounting for 104 (23.9\%) of the overall maternal deaths. The majority of deaths due to obstetric haemorrhage $(N=81 ; 77.8 \%)$ were caused by postpartum haemorrhage. On the other hand, postpartum haemorrhage accounted for $18.6 \%$ of the overall maternal deaths. The DOCFR varied considerably with the complications that occurred. The highest DOCFR was observed in postpartum haemorrhage $2.88 \%$ (95\% CI: $2.29-3.57 \%$ ) followed by ruptured uterus 2.71\% (95\% CI: $1.95-3.65 \%$ ). The DOCFR due to hypertensive disorders $1.53 \%$ (95\% CI: $1.27-1.82 \%$ ) and postpartum sepsis $1.16 \%$ (95\% CI: $0.67-1.85 \%)$ were also in excess of the recommended level (Table 2).

\section{Regional variations in the direct obstetric case fatality rate}

Although the crude national DOCFR was within the recommended threshold of less than 1\%, considerable regional variation occurred. The DOCFR ranged from $0.27 \%$ (95\% CI: $0.20-0.37 \%$ ) in Addis Ababa city administration to $3.82 \%$ (95\% CI: $1.42-8.13 \%$ ) in the Gambella region. The DOCFR was significantly higher in the Afar 1.39 (95\% CI: 0.45-3.22), the Harari 1.08 (95\%CI: 0.611.78 ) and the Somali 1.69 (95\% CI: 1.13-2.42) regions (Table 3).

\section{Determinants of the direct obstetric case fatality rate among hospitals}

Bivariate and multivariate logistic regression analyses were conducted to analyse the hospital specific determinants of the magnitude of DOCFR. In the final multivariate analysis, whether formal payment was required for the service or not, types and managing authority of the hospitals were found to be significantly associated with the magnitude of DOCFR after possible confounders were controlled for. The odds of observing DOCFR $\geq 1$ was reduced by $58 \%$ in general hospitals as compared to primary hospitals $[\mathrm{AOR}=0.42 ; 95 \% \mathrm{CI}$ $(0.21,0.85)]$. The magnitude of DOCFR was also lower in specialized hospitals compared to primary hospitals although the difference was not statistically significant. Regarding managing authorities, the odds of DOCFR $\geq 1$ was about two times higher in public/governmental hospitals than private counterparts $[\mathrm{AOR}=2.46 ; 95 \% \mathrm{CI}$ $(1.28,4.32)]$. Payment was also identified as a factor in that the odds of DOCFR $\geq 1$ was $64 \%$ higher in hospitals where formal payment was not required for the service than in hospitals where mothers need to cover service fee $[\mathrm{AOR}=1.64$; 95\%CI $(1.04,3.19)$ ]. This might be explained by differences in quality of care between public and private hospitals. In private hospitals where clients need to cover costs associated with health service, better quality of obstetric care were provided than it was in public hospitals (Table 4).

\section{Discussion}

This study evaluated the DOCFR and determinant factors among women who were admitted to Ethiopian hospitals with direct maternal morbidity in 2015. Overall, the DOCFR among women who were admitted to hospitals was found to be $0.64 \%(435 / 68,002)$. Prolonged labour was the leading cause of direct obstetric morbidity followed by hypertensive disorders. Hypertensive disorders of pregnancy, maternal haemorrhage, ruptured uterus and prolonged labour were the predominant direct causes of maternal deaths. The DOCFR was significantly higher among mothers who were admitted with postpartum haemorrhage and ruptured uterus. The DOCFR was also unacceptably high among mothers who experienced hypertensive disorders and sepsis. Significant regional variation was observed in the DOCFR, the highest being occurred in the Gambella region while the lowest was observed in Addis Ababa city administration, the capital city of Ethiopia.

The current study showed that in 2015, a large proportion (20.3\%) of women who gave birth in hospitals experienced the direct obstetric complications $(68,002 /$ $335,054)$. This finding is unsurprising as an estimated $15 \%$ of all pregnancies ended in obstetric complications [1]. Consistent with findings of an Eritrean study [18], 
Table 4 Unadjusted and adjusted logistic regression model of factors associated with maternal deaths among hospital in Ethiopia, 2015

\begin{tabular}{|c|c|c|c|c|c|c|}
\hline \multirow[t]{2}{*}{ Variables } & \multirow[t]{2}{*}{ Responses } & \multicolumn{2}{|c|}{ DOCFR } & \multirow{2}{*}{$\begin{array}{l}\text { Unadjusted } \\
\text { Odds ratio }\end{array}$} & \multirow{2}{*}{$\begin{array}{l}\text { Adjusted } \\
\text { Odds ratio }\end{array}$} & \multirow[t]{2}{*}{$P$ value } \\
\hline & & $\geq 1$ & $\overline{<1}$ & & & \\
\hline \multirow[t]{3}{*}{ Type of hospitals } & Referral hospital & 5 & 25 & $0.83(0.29,2.41)$ & $0.97(0.33,2.93)$ & 0.964 \\
\hline & General hospital & 25 & 78 & $0.27(0.27,0.98)$ & $0.42(0.21,0.85)$ & 0.016 \\
\hline & Primary hospital & 23 & 137 & Ref & Ref & \\
\hline \multirow[t]{2}{*}{ Managing authority } & Public/Government & 49 & 186 & $3.55(1.27,9.86)$ & $2.16(1.28,4.32)$ & 0.032 \\
\hline & Private & 4 & 54 & Ref & Ref & \\
\hline \multirow[t]{2}{*}{ Location } & Rural & 5 & 16 & $1.45(0.52,4.03)$ & $0.87(0.21,3.53)$ & 0.851 \\
\hline & Urban & 48 & 224 & Ref & Ref & \\
\hline \multirow[t]{2}{*}{ Have electric supply } & No & 1 & 11 & $0.40(0.05,3.17)$ & $1.11(0.07,15.77)$ & 0.939 \\
\hline & Yes & 52 & 229 & Ref & Ref & \\
\hline \multirow[t]{2}{*}{ Have Water supply } & No & 3 & 7 & $1.98(0.49,7.31)$ & $3.11(0.50,19.35)$ & 0.223 \\
\hline & Yes & 50 & 231 & Ref & Ref & \\
\hline \multirow[t]{2}{*}{ Availability of functional toilet } & No & 3 & 5 & $2.82(0.65,11.08)$ & $2.22(0.45,10.89)$ & 0.323 \\
\hline & Yes & 50 & 235 & Ref & Ref & \\
\hline \multirow[t]{2}{*}{ Payment required for the service } & No & 23 & 30 & $2.02(1.09,3.72)$ & $1.64(1.04,3.19)$ & 0.023 \\
\hline & Yes & 66 & 174 & Ref & Ref & \\
\hline \multirow[t]{2}{*}{ System in place to waive service fee } & No & 25 & 133 & $0.71(0.38,1.28)$ & $0.79(0.41,1.52)$ & 0.490 \\
\hline & Yes & 28 & 105 & Ref & Ref & \\
\hline \multirow[t]{2}{*}{ The hospital implement MDSR } & No & 6 & 80 & $0.25(0.10,0.62)$ & $0.24(0.09,1.18)$ & 0.06 \\
\hline & Yes & 47 & 160 & Ref & Ref & \\
\hline
\end{tabular}

DOCFR Direct Obstetric Case Fatality Rate, MDRS Maternal Death Review and Reporting System

Hospitals were dichotomized based on the WHO recommendation of DOCFR: hospitals with DOCFR $\geq 1$ (unfavourable DOCFR or hospitals with the outcome of interest) and hospitals with DOCFR $<1$ (favourable DOCFR or hospitals without the outcome of interest)

our finding revealed that hypertensive disorders of pregnancy were the leading cause of maternal mortality. Similarly, our study revealed that postpartum haemorrhage, prolonged labour and postpartum sepsis were the predominant causes of maternal mortality. Our finding is supported by Brazil's findings [19], findings in Kenya [20] and several small scale studies conducted in Ethiopia [21-23].

This study demonstrated that the crude national DOCFR was within the WHO recommended level of less than 1\% [9]. A significant reduction in the DOCFR was observed as compared to findings of a previous study where the national obstetric case fatality rate was $2 \%$ in 2008 [13]. This reduction might be explained by improved access to maternal health service, as the government of Ethiopia strengthened the health system while striving to achieve the Millennium Development Goals (MDGs) in reducing maternal mortality. The current finding is consistent with a study conducted in Indonesia, both in the magnitude and trends of the DOCFR [24].

Nevertheless, the current study demonstrated a considerable variation in the DOCFR among different direct causes of maternal deaths. Postpartum haemorrhage carried the highest DOCFR followed by ruptured uterus. The DOCFR for hypertensive disorders and postpartum sepsis also exceeded the recommended level. Our finding is consistent with the results of a systematic review conducted in sub-Saharan Africa where the case fatality rate of maternal haemorrhage, ruptured uterus, sepsis, and obstructed labour were higher than the recommended level [25]. Unlike our findings, a study conducted in six west African countries revealed higher DOCFR for sepsis (33.3\%), ruptured uterus (30.4\%) and hypertensive disorders of pregnancy (18.4\%) [17]. This variation might be attributed to the differences in sample size and study settings. While study of the West African countries assessed the DOCFR in sample of women, our study included data of all women that our findings were highly representative.

Despite lower DOCFR at the national level, a significant regional variation was observed. The highest DOCFR was observed in the Gambella region where case fatality rate was $3.82 \%$ (95\% CI: $1.42-8.13 \%$ ). A considerably high DOCFR was found in the Afar, Harari and Somali regions, the lowest being in Addis Ababa city administration; the capital city of Ethiopia. Our finding is supported with the study conducted in six west African 
countries where the case fatality rate significantly varied among the regions involved in the study [17]. The observed variation might be occurred due to the limited access to maternal health service in the Gambella, Afar and Somali regions as these regions are found in most pastoral area of the country. Higher DOCFR than the recommended level was noted in the Harari region one of the urban settings with better access to health service. This might be attributed to poor quality of obstetric care among hospitals found in the region. The observed regional disparities in the DOCFR might also be attributed to the existing regional differences in the use of antenatal care services [26] and the low quality of antenatal care in Ethiopia [27]. The existing spatial differences of contraceptive use among Ethiopian regions could also be a cause for the observed disparities in the DOCFR among regions [28].

In the multivariate logistic regression analyses, several hospital-specific factors were significantly associated with the magnitude of the DOCFR. In the final model, the likelihood of observing DOCFR $\geq 1$ was significantly reduced among general hospitals than it was in primary hospitals. The odds of having one or higher DOCFR was also decreased among specialized hospitals though the reduction was not statistically significant. The probability of maternal death from obstetric complications is usually affected with the type and quality of management provided at the facility. According to the three tier healthcare delivery system of Ethiopia, since specialized and general hospitals are more equipped with medical supplies and qualified healthcare providers than primary hospitals [29], this finding might not be surprising.

Although the difference is not statistically significant, the odds of having DOCFR $\geq 1$ was reduced by $75 \%$ among hospitals that did not implement the MDSR initiatives. The MDSR is a health reform used to continuously notify, review, analyse and respond to maternal deaths in order to take action to prevent similar deaths in the future [30]. Although, MDSR was accepted at subnational level in many countries, it is not adequately institutionalised [31]. Several barriers including role confusion, high staff turnover and lack of necessary facilities impeded the implementation of the MDSR reform [32]. Furthermore, the observed association might reflect the situation of private hospitals where quality of the service is better but the reform was not yet well institutionalized.

However, the odds of having DOCFR $\geq 1$ among public hospitals was two times higher as compared to private hospitals counterparts. This might be explained by the better health service utilization rate at private facilities than public counterparts [33]. This difference might also be observed due to better quality of the service as more standardized maternal health service is provided in private sector [34]. The observed difference in the magnitude of death might also be attributed to that most of the private hospitals (faith based and missionary) are mainly located in rural areas where women can accessed to treatment before sequel to severe complications [35].

The current study showed higher odds of having DOCFR $\geq 1$ among hospitals where formal payment for service was not required. Studies indicated that officialising the user charges creates financial barriers and reduces utilisation of maternal health service [36]. Access to the maternal health services is also limited with an informal payments for purchasing essential medicines [37]. On the other hand, introduction of user fee exemption reforms increased maternal health services utilization [38]. Improved access to the health service of good quality significantly decreases the maternal mortality rate [39]. Higher risk of DOCFR in hospitals where service are rendered for free might be attributed to the higher maternal mortality in public hospitals where maternity services are rendered free of charge as opposed to private hospitals.

\section{Strength and limitation of the study}

This study has several strengths. In this study, we used a national representative data collected from all hospitals found in Ethiopia. Therefore, the findings of this study are highly generalizable and can apply to all regions of Ethiopia. These findings might also be useful for other low-income countries with similar demographic and economic characteristics. From the commencement of the survey, experts from national and international partners were involved in the data collection and management processes hence the analysed data were of high quality. In the meantime, this study was suffered from the usual limitation of a cross-sectional study in that the causal relationship could not be concluded. This study did not investigate the maternal morbidity and mortality happened at the lower level of care including health centers and clinics. Although the majority of women who experienced obstetric complications are often referred to hospitals, few women might sometimes seek care from lower level facilities. Therefore, the findings of this study can only be generalized to hospitals in the country. The maternal deaths reported in this study represent only the numbers, which were registered on the hospital's logbook. Therefore, the number of deaths might be affected by maternal deaths that happened at home, which accounts for the majority of maternal deaths in lowincome countries. Similarly, we faced difficulties in comparing our findings with similar reports since there were limited similar studies available in Ethiopia.

\section{Conclusions}

This study revealed that the overall national DOCFR among hospitals was within the recommended threshold of less than $1 \%$, although considerable variation was 
observed among the different direct causes. Certain obstetric complications such as postpartum haemorrhage, ruptured uterus, sepsis, and hypertensive disorders carried a higher risk of death for women. Considerable regional differences occurred with regard to the DOCFR. Variation in the DOCFR among different regions of Ethiopia suggests that quality of obstetric care provided at hospitals of some regions might be unsatisfactory. Therefore, the government of Ethiopia needs to focus on quality improvement initiatives by taking regional variations in to consideration. Equitable resource distribution needs to be in place to tackle the regional disparities that exist. Further studies with a strong design should be conducted to investigate the relationship between different obstetric morbidity, the level of care and the individual risk factors that determine maternal deaths of the direct obstetric complications. Future studies should also include home-based deliveries and maternal morbidity and mortality that occurred at lower level of care to ensure representativeness.

\section{Abbreviations \\ APH: Antepartum Haemorrhage; AVD: Assisted Vaginal Delivery; CS: Caesarean Section; DOCFR: Direct Obstetric Case Fatality Rate; EmONC: Emergency Obstetric and Newborn Care; EPHI: Ethiopian Public Health Institute; HREC: Health Research Ethics Committee; IRB: Institutional Review Board; MDRS: Maternal Deaths Review and Report; MMR: Maternal Mortality Rate; PPH: Postpartum Haemorrhage; SVD: Spontaneous Vaginal Delivery; WHO: World Health Organization}

\section{Acknowledgements \\ The authors would like to acknowledge the University of Newcastle, Australia for providing a full PhD scholarship for the principal author of this paper. Our gratitude extends to the EPHI and the researchers who conducted the survey for their permission to access the data. We also extend our appreciations to the participant hospitals, data collectors, supervisors and the partners who have cooperated during the data collection process. Last but not least, we would like to thank Natalia Soeters for providing language revision and proof reading of the manuscript.}

\section{Authors' contributions}

AG and TT have developed the draft proposal under the supervision of CC and DL. CC and DL critically reviewed, provided substantive feedback and contributed to the intellectual content of this paper. All authors (AG, CC, TT and $\mathrm{DL}$ ) have made substantial contributions to the conception, design of the work, the acquisition, analysis and interpretation of data. All authors read and approved the final version of this manuscript.

\section{Authors' information}

AG is a PhD student at the University of Newcastle, and has a Master of Public Health and is currently working at the College of Health and Medical Science, School of Public Health, Haramaya University Harar, Ethiopia. CC (PhD) is a postdoc fellow and she is currently working at the Research Centre for Generational Health and Aging, University of Newcastle, Australia. $\Pi$ is a researcher, has a Master of Public Health, and is currently working at the Health Service Directorate, Ethiopian Public Health Institute, Ethiopia. DL (Prof) is a Professor of Public Health and she is currently working at the Research Centre for Generational Health and Ageing, University of Newcastle, Australia.

\section{Funding}

The analysis made for this data has no specific funding organization.

\section{Availability of data and materials}

The data that support the findings of this study are available from EPHI but restrictions apply to the availability of these data, which were used under license for the current study, and so are not publicly available. Data are however available from the authors upon reasonable request and with permission of the EPHI.

\section{Ethics approval and consent to participate}

This study was granted ethical approval from the Human Research Ethics Committee (HREC) of The University of Newcastle, Australia (approval number: $\mathrm{H}$-2018-0245) and the Scientific and Ethical Review Office of Ethiopian Public Health Institute (Protocol number: EPHI-IRB-048-2018).

\section{Consent for publication}

During the survey, the EPHI obtained the consent for publication from managers of all hospitals.

\section{Competing interests}

The authors declare that they have no competing interests.

\section{Author details}

${ }^{1}$ School of Public Health, College of Health and Medical Sciences, Haramaya University, Harar, Ethiopia. ${ }^{2}$ Research Centre for Generational Health and Ageing, School of Medicine and Public Health, Faculty of Health and Medicine, the University of Newcastle, Newcastle, Australia. ${ }^{3}$ Health System and Reproductive Health Directorate, the Ethiopian Public Health Institute, Addis Ababa, Ethiopia.

Received: 8 August 2019 Accepted: 20 February 2020

Published online: 27 February 2020

\section{References}

1. WHO. Trends in maternal mortality: 1990 to 2010. 2012

2. Sikder SS, Labrique AB, Ullah B, Ali H, Rashid M, Mehra S, et al. Accounts of severe acute obstetric complications in rural Bangladesh. BMC Pregnancy Childbirth. 2011;11(1):76.

3. Say L, Chou D, Gemmill A, Tunçalp Ö, Moller A-B, Daniels J, et al. Global causes of maternal death: a WHO systematic analysis. Lancet Glob Health. 2014;2(6):e323-e33.

4. Molina G, Esquivel MM, Uribe-Leitz T, Lipsitz SR, Azad T, Shah N, et al. Avoidable maternal and neonatal deaths associated with improving access to caesarean delivery in countries with low caesarean delivery rates: an ecological modelling analysis. Lancet. 2015;385(Suppl 2):S33. https://doi.org/ 10.1016/S0140-6736(15)60828-5.

5. Alkema L, Chou D, Hogan D, Zhang S, Moller A-B, Gemmill A, et al. Global, regional, and national levels and trends in maternal mortality between 1990 and 2015, with scenario-based projections to 2030: a systematic analysis by the UN maternal mortality estimation inter-agency group. Lancet. 2016; 387(10017):462-74.

6. World Health Organization. Trends in maternal mortality 2000 to 2017: estimates by WHO, UNICEF, UNFPA, World Bank Group and the United Nations Population Division. 2019.

7. Ethiopian Demographic and Health Survey, key indicators. Rockville: CSA, ICF; 2016.

8. WHO. Maternal mortality fact sheet. Geneva: World Health Organization; 2016.

9. World Health Organization. A hand book: Monitoring emergency obstetric care: a handbook. New York: World Health Organization; 2009.

10. United Nations Population Fund. Monitoring emergency obstetric care: a handbook. New York: World Health Organization; 2009.

11. Abegunde D, Kabo IA, Sambisa W, Akomolafe T, Orobaton N, Abdulkarim M, et al. Availability, utilization, and quality of emergency obstetric care services in Bauchi state, Nigeria. Int J Gynaecol Obstet. 2015;128(3):251-5.

12. Kongnyuy EJ, Hofman J, Mlava G, Mhango C, van den Broek N. Availability, utilisation and quality of basic and comprehensive emergency obstetric care services in Malawi. Matern Child Health J. 2009;13(5):687-94.

13. Admasu K, Haile-Mariam A, Bailey P. Indicators for availability, utilization, and quality of emergency obstetric care in Ethiopia, 2008. Int J Gynaecol Obstet. 2011;115(1):101-5

14. Federal Ministry of Health Ethiopia. Health Sector Transformation Plan, HSTP 2015/16-2019/20, (2008-2012 EFY). 2015. 
15. Worldometers population. Ethiopia Population (1950-2017), August 7/2017 2017 [Available from: http://www.worldometers.info/world-population/ ethiopia-population/. Accessed 27 July 2019.

16. Ethiopian Mini Demographic and Health Survey 2019. Rockville: Ethiopian Public Health Institute, FMo, ICF; 2019.

17. Prual A, Bouvier-Colle M-H, Bernis L, Breart G. Severe maternal morbidity from direct obstetric causes in West Africa: incidence and case fatality rates. Bull World Health Organ. 2000;78:593-602.

18. Ghebrehiwet M, Sharan M, Rogo K, Gebreamlak O, Haile B, Gaim M, et al Magnitude and causes of maternal deaths at health facilities in Eritrea in 2007. J Eritrean Med Assoc. 2009:4(1):22-5.

19. Esteves-Pereira AP, Deneux-Tharaux C, Nakamura-Pereira M, Saucedo M, Bouvier-Colle MH, Leal MC. Caesarean delivery and postpartum maternal mortality: a population-based case control study in Brazil. PLoS One. 2016; 11(4):e0153396.

20. Liambila WN, Kuria SN. Birth attendance and magnitude of obstetric complications in Western Kenya: a retrospective case-control study. BMC Pregnancy Childbirth. 2014;14(1):311.

21. Berhan $Y$, Berhan A. Causes of maternal mortality in Ethiopia: a significant decline in abortion related death. Ethiop. 2014;24:15-28.

22. Legesse T, Misra Abdulahi AD. Trends and causes of maternal mortality in Jimma University specialized hospital, Southwest Ethiopia: a matched casecontrol study. Int J Womens Health. 2017;9:307.

23. Tessema GA, Laurence CO, Melaku YA, Misganaw A, Woldie SA, Hiruye A, et al. Trends and causes of maternal mortality in Ethiopia during 1990-2013: findings from the global burden of diseases study 2013. BMC Public Health. 2017:17(1):160

24. Ahmed S, Tholandi M, Pedrana A, Zazri A, Parmawaty N, Rahmanto A, et al. Changes in obstetric case fatality and early newborn mortality rates in hospitals after the implementation of the expanding maternal and neonatal survival program in Indonesia: results from a health information system. Int J Gynecol Obstet. 2019;144:13-20.

25. Kaye DK, Kakaire O, Osinde MO. Systematic review of the magnitude and case fatality ratio for severe maternal morbidity in sub-Saharan Africa between 1995 and 2010. BMC Pregnancy Childbirth. 2011;11(1):65.

26. Yesuf EA, Calderon-Margalit R. Disparities in the use of antenatal care service in Ethiopia over a period of fifteen years. BMC Pregnancy Childbirth. 2013;13(1):131

27. Muchie KF. Quality of antenatal care services and completion of four or more antenatal care visits in Ethiopia: a finding based on a demographic and health survey. BMC Pregnancy Childbirth. 2017;17(1):300.

28. Lakew Y, Reda AA, Tamene H, Benedict S, Deribe K. Geographical variation and factors influencing modern contraceptive use among married women in Ethiopia: evidence from a national population based survey. Reprod Health. 2013;10(1):52.

29. Federal Ministry of Health Ethiopia. Health Sector Transformation Plan 2015/ 16-2019/20. 2015

30. WHO. Time to respond: A report on the global implementation of Maternal Death Surveillance and Response 2016.

31. Smith H, Ameh C, Roos N, Mathai M, van den Broek N. Implementing maternal death surveillance and response: a review of lessons from country case studies. BMC Pregnancy Childbirth. 2017;17(1):233

32. Abebe B, Busza J, Hadush A, Usmael A, Zeleke AB, Sita S, et al. 'We identify, discuss, act and promise to prevent similar deaths': a qualitative study of Ethiopia's Maternal Death Surveillance and Response system. BMJ Glob Health. 2017;2(2):e000199.

33. Boller C, Wyss K, Mtasiwa D, Tanner M. Quality and comparison of antenatal care in public and private providers in the United Republic of Tanzania. Bull World Health Organ. 2003;81:116-22.

34. Chen L, Dai Y, Zhang Y, Wu Q, Rudan D, Saftić V, et al. A comparison between antenatal care quality in public and private sector in rural Hebei, China. Croatian Med J. 2013;54(2):146-56.

35. Tabatabai P, Henke S, Sušac K, Kisanga OM, Baumgarten I, Kynast-Wolf G, et al. Public and private maternal health service capacity and patient flows in southern Tanzania: using a geographic information system to link hospital and national census data. Glob Health Action. 2014:7(1):22883.

36. Danilovich N, Yessaliyeva E. Effects of out-of-pocket payments on access to maternal health services in Almaty, Kazakhstan: a qualitative study. Eur Asia Stud. 2014;66(4):578-89.

37. Sumankuuro J, Crockett J, Wang S. Perceived barriers to maternal and newborn health services delivery: a qualitative study of health workers and community members in low and middle-income settings. BMJ Open. 2018; 8(11):e021223.

38. Hatt LE, Makinen M, Madhavan S, Conlon CM. Effects of user fee exemptions on the provision and use of maternal health services: a review of literature. J Health Popul Nutr. 2013;31(4 Suppl 2):S67.

39. Lindtjørn B, Mitiku D, Zidda Z, Yaya Y. Reducing maternal deaths in Ethiopia: results of an intervention Programme in Southwest Ethiopia. PLoS One. 2017;12(1):e0169304

\section{Publisher's Note}

Springer Nature remains neutral with regard to jurisdictional claims in published maps and institutional affiliations.
Ready to submit your research? Choose BMC and benefit from:

- fast, convenient online submission

- thorough peer review by experienced researchers in your field

- rapid publication on acceptance

- support for research data, including large and complex data types

- gold Open Access which fosters wider collaboration and increased citations

- maximum visibility for your research: over $100 \mathrm{M}$ website views per year

At BMC, research is always in progress.

Learn more biomedcentral.com/submissions 